\title{
Tracing Fuel Component Carbon in the Emissions from Diesel Engines
}

B.A. Buchholz,C.J. Mueller, G.C. Martin, A.S. Cheng, R.W. Dibble, and B.R. Frantz

This paper was submitted to The $9^{\text {th }}$ International Conference on Accelerator Mass Spectrometry, Nagoya, Japan, September 9-13, 2002

\section{October 14, 2002}




\section{DISCLAIMER}

This document was prepared as an account of work sponsored by an agency of the United States Government. Neither the United States Government nor the University of California nor any of their employees, makes any warranty, express or implied, or assumes any legal liability or responsibility for the accuracy, completeness, or usefulness of any information, apparatus, product, or process disclosed, or represents that its use would not infringe privately owned rights. Reference herein to any specific commercial product, process, or service by trade name, trademark, manufacturer, or otherwise, does not necessarily constitute or imply its endorsement, recommendation, or favoring by the United States Government or the University of California. The views and opinions of authors expressed herein do not necessarily state or reflect those of the United States Government or the University of California, and shall not be used for advertising or product endorsement purposes.

This is a preprint of a paper intended for publication in a journal or proceedings. Since changes may be made before publication, this preprint is made available with the understanding that it will not be cited or reproduced without the permission of the author.

This report has been reproduced directly from the best available copy.

Available to DOE and DOE contractors from the

Office of Scientific and Technical Information

P.O. Box 62, Oak Ridge, TN 37831

Prices available from (423) 576-8401

http:/ /apollo.osti.gov/bridge/

Available to the public from the

National Technical Information Service

U.S. Department of Commerce

5285 Port Royal Rd., Springfield, VA 22161

http://www.ntis.gov/

OR

Lawrence Livermore National Laboratory Technical Information Department's Digital Library

http://www.llnl.gov/tid/Library.html 


\section{Tracing Fuel Component Carbon in the Emissions From Diesel Engines}

Bruce A. Buchholz ${ }^{1}$, Charles J. Mueller ${ }^{2}$, Glen C. Martin ${ }^{2,3}$, A. S. (Ed) Cheng ${ }^{4}$ and Robert W. Dibble ${ }^{4}$, Brian R. Frantz ${ }^{1}$

${ }^{1}$ Center for AMS, Lawrence Livermore National Laboratory, Livermore, CA USA

${ }^{2}$ Combustion Research Facility, Sandia National Laboratory, Livermore, CA USA

${ }^{3}$ Mechanical Engineering Department, University of Illinois, Urbana, IL USA

${ }^{4}$ Mechanical Engineering Department, University of California, Berkeley, CA USA

Contact Author:

Bruce A. Buchholz

CAMS, L-397

Lawrence Livermore National Laboratory

P.O. Box 808

Livermore, CA 94551-9900

USA

VOI: $\quad 1-925-422-1739$

FAX: $1-925-423-7884$

Email: buchholz2@1lnl.gov 


\section{Abstract}

The addition of oxygenates to diesel fuel can reduce particulate emissions, but the underlying chemical pathways for the reductions are not well understood. While measurements of particulate matter (PM), unburned hydrocarbons (HC), and carbon monoxide $(\mathrm{CO})$ are routine, determining the contribution of carbon atoms in the original fuel molecules to the formation of these undesired exhaust emissions has proven difficult. Renewable bio-derived fuels (ethanol or bio-diesel) containing a universal distribution of contemporary carbon are easily traced by accelerator mass spectrometry (AMS). These measurements provide general information about the emissions of bio-derived fuels. Another approach exploits synthetic organic chemistry to place ${ }^{14} \mathrm{C}$ atoms in a specific bond position in a specific fuel molecule. The highly labeled fuel molecule is then diluted in ${ }^{14} \mathrm{C}$-free petroleum-derived stock to make a contemporary petroleum fuel suitable for tracing. The specific ${ }^{14} \mathrm{C}$ atoms are then traced through the combustion event to determine whether they reside in $\mathrm{PM}, \mathrm{HC}, \mathrm{CO}, \mathrm{CO}_{2}$, or other emission products. This knowledge of how specific molecular structures produce certain emissions can be used to refine chemical-kinetic combustion models and to optimize fuel composition to reduce undesired emissions. Due to the high sensitivity of the technique and the lack of appreciable ${ }^{14} \mathrm{C}$ in fossil fuels, fuels for AMS experiments can be labeled with modern levels of ${ }^{14} \mathrm{C}$ and still produce a strong signal. Since the fuel is not radioactive, emission tests can be conducted in any conventional engine lab, dynamometer facility, or on the open road. 


\section{Introduction}

Environmental concerns over the effects of emissions from internal combustion engines drives emission standards to lower levels and stimulates interest in nonconventional fuels and additives. Oxygenated fuels can dramatically reduce particulate matter (PM) generated by diesel engines while not adversely affecting levels of other regulated emissions $\left(\mathrm{CO}, \mathrm{NO}_{\mathrm{x}}\right.$ and hydrocarbons $\left.(\mathrm{HC})\right)$ [1-10]. The mechanisms through which oxygenates reduce PM, however, are poorly understood.

If combustion mechanisms are understood, then modeling can be used to evaluate changes in fuel formulation and suggest possible fuel components that can improve combustion, reduce emissions, and expand the fuel supply. It has been proposed that the mass fraction of oxygen in a fuel is the primary factor governing PM formation [5], but the role of different carbon bond types has not been explored thoroughly. AMS allows the labeling of specific carbon atoms within fuel components to follow the fate of these atoms and develop accurate combustion mechanisms for specific chemical structures.

The petroleum base of most diesel fuel provides a very low ${ }^{14} \mathrm{C}$ background, $<1 \times 10^{-15}{ }^{14} \mathrm{C} / \mathrm{C}$. Bio-derived fuels (ethanol, bio-diesel) have contemporary ${ }^{14} \mathrm{C} / \mathrm{C}$ concentrations about 1000 times the instrumental petroleum background and are easily traced in emissions. The most precise tracing technique uses a pure custom synthesized compound with the ${ }^{14} \mathrm{C}$ label in a specific position in a fuel molecule. With this approach, the propensity of specific molecular structures (carbon-carbon double bonds, carbon-oxygen bonds, esters, etc.) to form specific emission products can be measured. 
The methods described below for tracing fuel components in diesel engine emissions can be applied to any combustion system. The low level of ${ }^{14} \mathrm{C}$ needed for AMS quantification allows tracing in conventional engine labs, dynamometer facilities, or the open road. Our objectives here are to describe basic methods and present early data on the partitioning of oxygenate-derived carbon in $\mathrm{PM}$ and $\mathrm{CO}_{2}$ emissions.

\section{Facilities, Materials and Methods}

The ${ }^{14} \mathrm{C}$ background of the engine labs at Sandia National Laboratories (SNL) and UC-Berkeley (UCB) were checked with swipes and aerosol monitors prior to starting any experiments [11]. The SNL alternative fuels optical engine laboratory features a singlecylinder version of a modern-technology, Caterpillar 4-stroke direct injection (DI) diesel engine. This engine has been modified by SNL to provide extensive optical access into the combustion chamber to enable observation of in-cylinder combustion processes using advanced laser/imaging diagnostics as well as precise control of operating parameters $[12,13]$. The engine is based on the Caterpillar 3176/C-10 platform (261 kW version) used in heavy-duty trucking. The UCB facility has a 1993 Cummins B5.9 Diesel engine, a 6 cylinder 5.9 liter turbocharged and aftercooled diesel engine rated at $130 \mathrm{~kW}$. No modifications were made to the UCB engine or fuel injection system to optimize for operation on the test fuels.

The ${ }^{14} \mathrm{C}$ content of all major fuel components and lubrication oils were measured prior to conducting the engine tests. The fuel used at SNL was blended from an 
oxygenated hydrocarbon, dibutyl maleate (DBM) (88.0 vol\%); a paraffinic hydrocarbon, n-hexadecane (7.0 vol\%); and an ignition improver, 2-ethylhexyl nitrate (5.0 vol\%). The ignition improver was required to achieve the desired ignition delay of $400 \mu$ s under the current operating conditions ( $900 \mathrm{~K}$ and 60 bar at top dead center when motored at $1200 \mathrm{rpm})$. The high concentration of DBM in the fuel was selected to study the combustion of the oxygenated hydrocarbon without the complication of high dilution in a conventional diesel fuel. Although the optical features of the engine were not exploited in this study, combustion of this fuel blend has been examined in detail at SNL [13]. Radiolabeled DBM was purchased from custom synthesis suppliers, Moravek Biochemicals, Inc. of Brea, California and ARC of St. Louis, Missouri. Separate 4-L volumes of fuel were blended with tracer ${ }^{14} \mathrm{C}$ located in different positions of the maleate; [maleate-1,4- ${ }^{14} \mathrm{C}$ ]- DBM (80 pMC) and [maleate-2,3- $\left.{ }^{14} \mathrm{C}\right]-\mathrm{DBM}(88 \mathrm{pMC})$ (see Fig. 1).

The fuels used in the UCB engine were baseline diesel fuel and blends of baseline diesel with bio-derived ethanol to achieve the same total oxygen concentration. Table 1 lists fuel blends and ${ }^{14} \mathrm{C}$ content of the major constituents in the UCB fuels. Because ethanol is soluble in diesel fuel in only small quantities, either an emulsifier (Span 85, i.e. sorbitan trioleate) or a cosolvent (n-butanol) was used to prepare the ethanol-in-diesel blends. An ignition improver, di-tert-butyl peroxide (DTBP), was also used to compensate for the low cetane number of ethanol and to give all blends the same ignition delay as the baseline diesel. The ${ }^{14} \mathrm{C}$ content of this diesel fuel is higher than expected for 
a petroleum product, probably due to small amounts of contemporary carbon detergents. The contemporary carbon from the ethanol is the tracer in these fuels.

All PM samples were collected on precombusted (1173 K, 3h) Gelman Sciences PALLFLEX tissuequartz 2500QAT-UP membrane filters, $37 \mathrm{~mm}$ at SNL and $47 \mathrm{~mm}$ at UCB. With the SNL engine operating in skip-fired mode (fired every $12^{\text {th }}$ cycle), a minimum of 48 fires were required to deposit sufficient soot for isotopic analysis. In practice, however, collecting PM over 96 fires produced a larger sample that was easier to process and analyze by AMS. Filters were handled with stainless steel forceps, transferred to a sealable plastic bag after loading and placed in a dark opaque envelope. Several motored-only filters were also collected during each day of runs to ascertain the background from uncombusted lubrication oil collected on the filters during non-fired cycles. At the completion of the experiments for each day, the samples were taken to the natural carbon AMS prep lab at LLNL for processing. At UCB, blank filters were first conditioned to ambient temperature and humidity overnight in petri dishes and then individually weighed with a Mettler UM 3 microbalance. Exhaust gases were diluted to obtain a gas temperature of $325 \mathrm{~K}$; resulting dilution ratios ranged between approximately 6 and 14. The engine was operated at steady-state conditions of $1600 \mathrm{rpm}$ and $285 \mathrm{~N}-\mathrm{m}$. Diluted exhaust was drawn through each filter for 10 minutes and the filters were then removed, placed in petri dishes and once again conditioned overnight before weighing. Four separate samples were taken for each point in the test matrix. A series blank was collected for each set of filters. 
Combustion gas samples were collected in Tedlar bags placed after the filter holder in the exhaust line. Each bag had a conventional fill valve and second septa seal port. The septa port was used to remove gas for AMS sample preparation. Gas samples were processed within several days of collection. Water, sulfur dioxide, and unburned fuel were removed using a dry ice-isopropyl alcohol cold trap. The $\mathrm{CO}_{2}$ was then cryogenically condensed in a liquid nitrogen cold trap and non-condensable gases $\left(\mathrm{N}_{2}\right.$, $\mathrm{NO}_{\mathrm{x}}$ ) were removed. The $\mathrm{CO}_{2}$ was then moved to a graphitization head [14] for conversion to an AMS graphite sample.

Beyond measuring total PM emissions, we sought to determine partitioning of the PM. In practice, the criteria for this separation are operationally defined by the investigator. Depending on the field of the investigator, the separation of PM carbon is commonly described by the following pairs: elemental and organic carbon, soluble organic fraction (SOF) and insoluble organic fraction (IOF), or volatile organic fraction (VOF) and non-volatile organic fraction (NVOF). We prefer the VOF/NVOF nomenclature because it reflects the process we use and the physical properties employed in any realistic exhaust treatment scheme.

Loaded filters were either placed in a quartz combustion tube with $\mathrm{CuO}$ oxidizer to combust to $\mathrm{CO}_{2}$ to measure total carbon or treated to remove the VOF. The treated filters were heated to $613 \mathrm{~K}$ for $2 \mathrm{~h}$ in a furnace and then allowed to cool to room temperature to remove the VOF. The VOF is estimated by measuring the difference between treated and untreated filters. Loaded filters lose mass during the thermal 
separation and the soot deposits are noticeably lighter in color. The remaining carbon is the NVOF. The filters with NVOF are then prepared as AMS samples with the usual procedure [14].

The procedure to remove the VOF was developed to obtain consistent isotope ratios and mass fraction of the NVOF from National Institute of Standards and Technology (NIST) standard reference material (SRM). NIST SRM 2975 (diesel soot) and SRM 1649a (urban dust) are the closest NIST SRMs to exhaust PM. Figure 2 depicts the variation in pMC of SRM 1649a when heated for $2 \mathrm{~h}$ in an oven and allowed to cool to room temperature. The pMC was not reproducible at temperatures above $613 \mathrm{~K}$. Since this is a reasonable operating temperature for in-line exhaust catalysts, we chose to adopt it for our VOF/NVOF separation.

\section{Results and Discussion}

All loaded filters contained sufficient carbon to produce adequate samples for analyses. In general, the UCB fleet engine operating with conventional dilution tunnel and gas analyzer technology produced large PM samples that were easy to analyze. The SNL optical engine operating in skip-fired mode produced much less PM while also loading the filters with significant amounts of unburned lubrication oil. The use of an isobutylene lubrication oil that cracked below $570 \mathrm{~K}$ allowed us to easily remove this oil with the VOF. The total carbon measurements that contain the VOF were dominated by the lubrication oil. 
The isotope content of the NVOF in the DBM fuels differed significantly. The 1,4 maleate carbons did not form soot. The carbon-oxygen double bond of the 1,4 maleate carbon remained intact during combustion and carried that carbon to $\mathrm{CO}_{2}$. The 2,3 maleate carbons participated in soot production about the same amount as normal diesel fuel. Molecular fragments with carbon-carbon double bonds are implicated in soot formation, so the 2,3 maleate is expected to be relatively sooty.

The ethanol-diesel blends produced several interesting results. Both emulsified and co-solvent blends reduced total PM, but ethanol-derived carbon was found in the PM. Baseline diesel fuel and the co-solvent blends both yielded 50/50 VOF/NVOF PM, but the emulsified blend shifted the partitioning closer to 80/20. Driving up the VOF is significant because VOF is more easily treated in standard exhaust treatment systems. The carbon mass produced by the co-solvent and emulsified blends were almost identical. The ethanol-derived carbon found in the PM tended to be found in the NVOF. In the case of the cosolvent blend, it appears that the ethanol-derived carbon resides primarily in the building blocks of soot rather than in condensed volatiles on the surface of the PM. The tendency of ethanol to produce acetylene and other soot precursors during combustion is supported by this data. Some of the loss of ${ }^{14} \mathrm{C}$ to the VOF for the emulsified blend appears to be associated with the emulsifier. Control experiments in which emulsifier was added to diesel without ethanol indicated that emulsifier-derived carbon resided mostly in the VOF. 


\section{Conclusions}

AMS provides a means of following the fate of carbon in specific compounds from the fuel to the emissions from diesel engines. Selective labeling of specific carbon atoms within a fuel component provides direct experimental evidence of the behavior of different chemical groups during combustion. In addition to providing data validation to combustion modelers, the data provides insights into which chemical structures within fuels and additives most greatly influence emissions.

The huge difference in the distribution of ${ }^{14} \mathrm{C}$ in DBM fuels provides direct evidence that neighboring atoms influence the formation of combustion products. The ease of using the contemporary tracer carbon in ethanol demonstrated the simple application to tracing bio-derived components of blended fuels. Although the majority of the ethanol-derived carbon was fully oxidized, more ethanol-derived carbon appeared in the PM than one might expect for a molecule containing so much oxygen. Differences in the PM produced with cosolvent and emulsified blends suggests that the distribution of oxygen in the fuel, not just its content, significantly affects PM production.

\section{Acknowledgements}

This work was performed under the auspices of the U.S. Department of Energy by the University of California, Lawrence Livermore National Laboratory under contract No. W-7405-Eng-48. The research at UCB was supported by LLNL Laboratory Directed Research and Development grant 01-ERI-007. The research at SNL was funded by the U.S. Department of Energy through a Cooperative Research and Development Agreement (CRADA \#SC99/01561). The authors thank Stephen Goguen and Gurpreet Singh of the Office of Heavy Vehicle Technologies, and John Garbak of the Office of Advanced Automotive Technologies at the U.S. Department of Energy for their support of this research. 


\section{References}

1. A.S. Cheng, R. W. Dibble, SAE Technical Paper 1999-01-3606 (1999).

2. F.J. Liotta, D. M. Montalvo, SAE Technical Paper 932734 (1993).

3. T. Fleisch, C. McCarthy, A. Basu, C. Udovich, P. Charbonneau, W. Slodowske, S. Mikkelsen, J. McCandless. SAE Technical Paper 950061 (1995).

4. R.L. McCormick, J. D. Ross, M. S. Graboski, Environ. Sci \& Tech. 31 (1997) 144.

5. N. Miyamoto, H. Ogawa, N. M. Nurun, K. Obata, T. Arima, SAE Technical Paper 980506 (1998).

6. M.M. Maricq, R. E. Chase, D. H. Podsiadilik, W. O. Siegel, E. W. Kaiser, SAE Technical Paper 982572 (1998).

7. C. Bertoli, N. Del Giacomo, C. Beatrice, SAE Technical Paper 972972 (1997).

8. W.G. Wang, D. W. Lyons, N. N. Clark, M. Gautam, P. M. Norton, Environ. Sci Tech. 34 (2000) 933.

9. M.A. Gonzalez, et al., SAE Technical Paper 2001-01-3632 (2001).

10. A.S. Cheng, R. W. Dibble, SAE Technical Paper 2001-01-2505 (2001).

11. P. Zermeño, D.K. Kurdyla, B.A. Buchholz, S.J. Heller, B.R. Frantz, T.A. Brown, M.Kashgarian, Nucl. Instr. And Meth. B (2003) this volume.

12. C.J. Mueller, M.P. Musculus, SAE Technical Paper 2001-01-2004 (2001).

13. C.J. Mueller, G. C. Martin, SAE Technical Paper 2002-01-1631 (2002).

14. J.S. Vogel, J. R. Southon, D. E. Nelson, Nucl. Instr. And Meth. B 29 (1987) 50. 
Table 1. UCB test fuel blends (components listed in volume percent except for oxygen which is mass percent) and ${ }^{14} \mathrm{C}$ content of components (amol ${ }^{14} \mathrm{C} / \mathrm{mg} \mathrm{C}$ ).

\begin{tabular}{|c|c|c|c|}
\hline $\begin{array}{c}\text { Fuel } \\
\text { Component }\end{array}$ & $\begin{array}{c}\text { Emulsified } \\
\text { Blend }\end{array}$ & $\begin{array}{c}\text { Cosolvent } \\
\text { Blend }\end{array}$ & $\begin{array}{c}{ }^{14} \mathrm{C} \\
\text { Content }\end{array}$ \\
\hline Diesel & 76.0 & 77.0 & 0.33 \\
\hline Ethanol & 18.5 & 18.0 & 107 \\
\hline SPAN 85 & 4.0 & - & 110 \\
\hline n-butanol & - & 3.5 & 0.09 \\
\hline DTBP & 1.5 & 1.5 & 0.01 \\
\hline Oxygen & 7.0 & 7.0 & NA \\
\hline
\end{tabular}

Figure 1. DBM molecule with the carbon atoms of the maleate numbered.

Figure 2. Variation in pMC of NIST SRM 1649a with baking temperature. Error bars are the size of the symbols. Heat treatment at temperatures at and below $613 \mathrm{~K}$ yielded reproducible $\mathrm{pMC}$ values. 


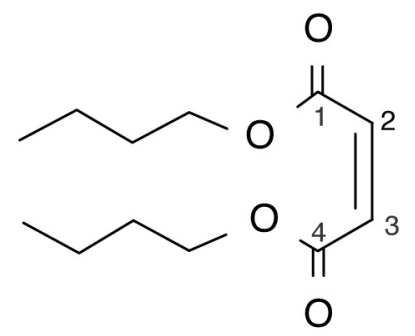




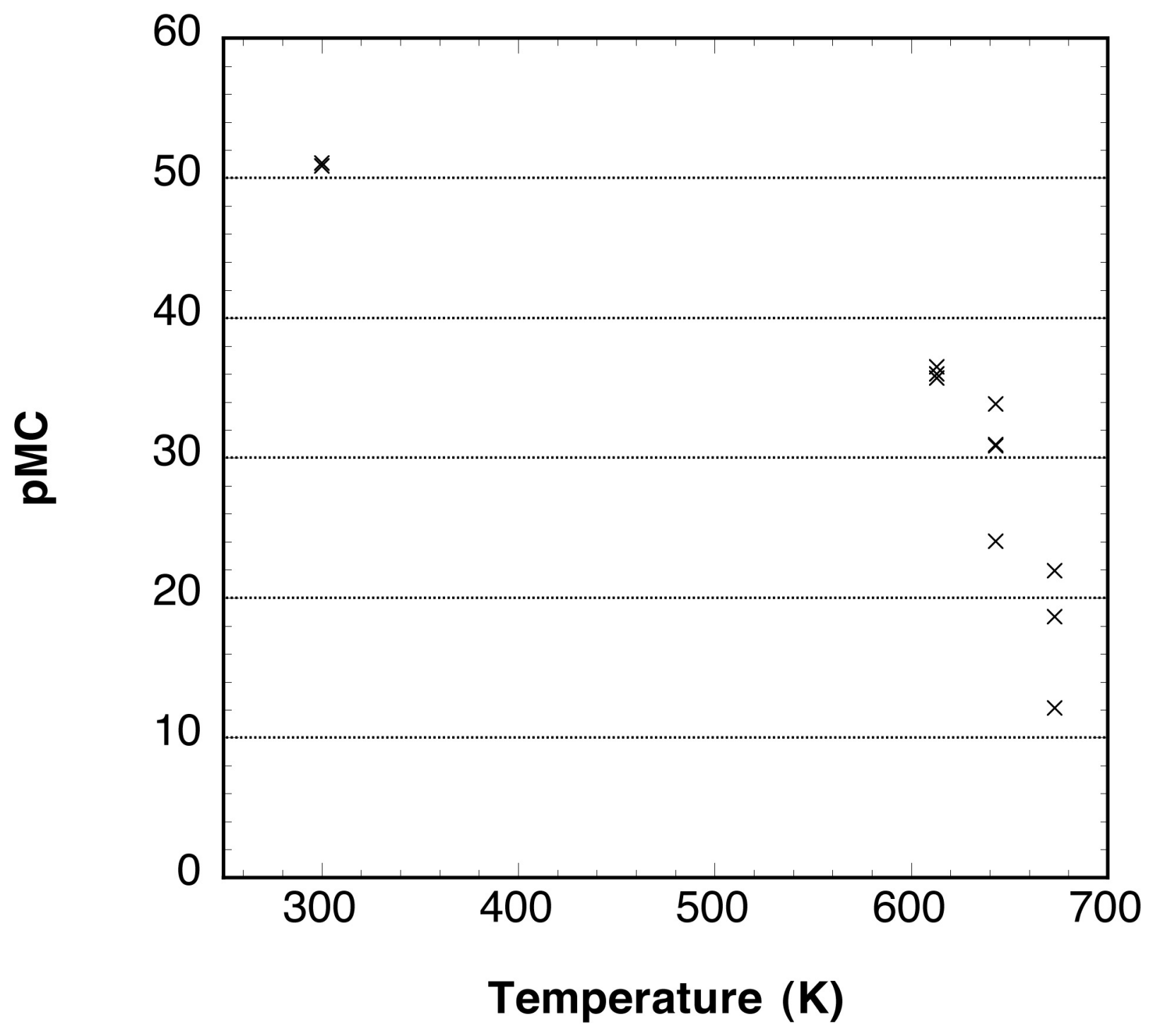

